\title{
MOVIMIENTO SOCIAL JUVENIL Y EJE CULTURAL Dos contextos de reconstrucción organizativa (1976-1982 / 1989-2002)
}

\section{VÍCTOR MUÑOZ TAMAYO*}

UN ACERCAMIENTO A LA historia de las organizaciones juveniles, nos habla de una motivación constante en los grupos, que es la autogestión cultural. Talleres artísticos literarios, festivales y múltiples espacios para la expresión, han sido instancias para que diversas agrupaciones juveniles dieran cuenta de su identidad, tan intensa como la vida de los jóvenes y sus incertezas, tan diversa como un mundo que se vive a partir de las particularidades sociales y epocales.

Desde una perspectiva de historia de los movimientos sociales, analizaremos aquí dos contextos en que una reconstrucción de movimiento social juvenil ha incluido notablemente la acción cultural como eje de su proceso de desarrollo. Se trata de reconstrucciones puesto que suceden tras momentos de quiebre de los movimientos juveniles, el primero, 1973, quiebre abrupto tras la violencia que trae el golpe de Estado, el miedo y la muerte que siembra en los sujetos sociales; el segundo, la transición política, un quiebre de desconcierto, procesos de autocrítica y crisis estructural de un movimiento social que no contaba con la suficiente base de autonomía para sobrellevar el cambio de contexto nacional y mundial con que se iniciaba la última década del siglo.

* Licenciado en Historia y egresado de maestría en ciencias sociales.

E-Mail: vmuñozt@mixmail.com. 
Tras el golpe militar de 1973, los jóvenes de las poblaciones, universidades y liceos ven fracturada su cotidianeidad. Las instancias de organización social desaparecen, al igual que los múltiples sueños colectivos que la juventud construyó en ellas. La angustia que todo esto provoca carece de formas colectivas de enfrentarla, y es que el sólo reagrupamiento se concibe como un peligro. De esta forma, gran parte de los jóvenes de 1973 se encontraban abruptamente sin sus instancias básicas de sociabilidad y formación identitaria.

Para ahondar en la historia de quienes volvieron a construir organización juvenil tras el golpe militar, hay que pensar en jóvenes diferentes a los de 1973. Por ejemplo, en quienes siendo niños y adolescentes durante el golpe, se habían llegado a identificar con símbolos e ideas fuerzas de la época previa al 73, configurándose como una generación intermedia que no siendo atacada directamente por la represión golpista, se sintió motivada a protagonizar nuevos procesos organizativos, rescatando elementos político culturales de la generación del 68. O pensar en aquellos que optaron por aprovechar la diversión que ofrecía el «boom de las discoteques», hasta que sintieron la necesidad de «hacer cosas» en los espacios silenciados, venciendo el miedo e imaginando grandes cambios a partir de referentes sociales y políticos clandestinos. ${ }^{1}$

Durante los años de dictadura, las organizaciones sociales de la juventud toman las formas de quienes las levantan. Por ejemplo, si en la base de su origen tienen peso determinadas estructuras o instituciones, es muy probable que la estructura organizacional reproduzca elementos organizativos de éstas, o al menos su influencia se perciba en las lógicas de acción que en su interior se desarrollen. Por ejemplo, si revisamos la historia de las organizaciones juveniles poblacionales, veremos una importante influencia de los partidos políticos hasta el año 1989, año de la transición a la democracia. En ese contexto las estructuras y lógicas de los partidos eran adquiridos por militantes sociales que en gran número eran también militantes partidistas. Posterior a ese año, la menor influencia de los partidos que pierden pre-

1 Para el estudio de la evolución de las organizaciones juveniles en dictadura, ver Irene Agurto, Gonzalo De la Maza y Manuel Canales: Juventud chilena: razones y subversiones. Santiago, ECO/FOLICO/SEPADE, 1985. Guillermo Campero: Entre la sobrevivencia y la acción política: las organizaciones de los pobladores en Santiago. Santiago, ILET, 1987. Andrés Undiks: Juventud urbana y exclusión social: las organizaciones de la juventud pobladora. Buenos Aires, Humanitas/FOLICO, 1989. 
sencia local, la nueva actitud de la Iglesia que acoge sólo a iniciativas pastorales dejando de ser «el espacio» de organizaciones que fue, y el alejamiento y nuevo rumbo de ONGS, causan que desde entonces, gran parte de las nuevas organizaciones tiendan a reproducir las estructuras y lógicas de acción originadas en el propio mundo social que les dio lugar, es decir, el grupo de amistades. A partir de entonces abundarán las estructuras horizontales que se resistirán a la lógica de los cargos que solicitan los trámites de personalidad jurídica, agrupaciones centradas en motivaciones de corte generacional en que el ser joven y crear identidad al respecto, serán puntos centrales. ${ }^{2}$

Sin embargo, en las poblaciones, este proceso no se desarrolla sin haber pasado antes por un quiebre abrupto que significó el término de gran parte del tejido social organizado que existió en dictadura. Quedaba al descubierto la dependencia del movimiento social respecto a instancias como la Iglesia, partidos y ONG, al punto que tras su crisis o alejamiento, el movimiento social juvenil no puede continuar autónomamente su desarrollo. A ello se le debe agregar la generalizada decepción por el modelo de transición triunfante y la crítica interna de las organizaciones respecto de las formas en que las dimensiones de lo social, lo político partidista y la acción cultural, se habían asumido hasta entonces.

Procesos similares ocurren en las universidades, donde crisis de partidos y federaciones gatillan la creación de pequeños colectivos que, asociándose entre sí, desarrollan gestiones socioculturales que a menudo amplían a un ámbito barrial que les permite trascender el tiempo y el espacio asociado a ser universitario.

Se trata entonces de dos quiebres, uno en medio del ruido de los tanques y otro silencioso tras una corta euforia marcada por el triunfo del NO en el plebiscito de 1988. Pero como en todo proceso de los movimientos sociales, cada quiebre presenta el germen de la reconstrucción, permitiendo el surgimiento de nuevas formas de organización, lógicas y apuestas que nos hablan de nuevos proyectos de construcción histórica.

2 Mauricio Rodríguez: «La conversación de los jóvenes pobladores organizados». Proposiciones №24. Santiago, Ediciones SuR, 1994. Víctor Muñoz Tamayo: «Por qué celebramos el primero de mayo aquí en la población y no en General Velázquez. Las organizaciones de la juventud pobladora y las dimensiones de lo social y lo político. 1990-1999». Investigación y Crítica No1. Santiago, LOM/ARCIS, 1999. 
¿Cuál ha sido el rol de la acción cultural en estos procesos? ¿Qué aprendizajes podemos obtener de la comparación de estos períodos? Son algunas de las preguntas que quienes construyen organización sociocultural y la valoran como instancia política, deben considerar. De ser así, efectivamente daríamos sentido a la memoria en la lucha por hacer la historia.

\section{LA RECONSTITUCIÓN ORGANIZATIVA Y EL EJE CULTURAL TRAS EL GOLPE MILITAR (1974-1982)}

Cuando se hace mención de la lucha social de los jóvenes contra la dictadura, usualmente se habla de la llamada generación de los ochenta. Esto no constituiría un sesgo si no fuese porque tal mención releva los procesos ocurridos tras la crisis económica de 1982 y las protestas nacionales de 1983, sin considerar los esfuerzos reconstructivos del movimiento social juvenil en los años anteriores.

Sin la presencia pública de los ochenta, el período de fines de los setenta y primeros años de la posterior década, constituyó un momento de reconstrucción a partir de la necesidad de reunirse y volver a reconocerse en una identidad de cambio social y recuperación democrática. Tal período parte en los años 1976-77, cuando la resistencia político partidista se asocia a los reagrupamientos que desde diversos espacios sociales comienzan a articularse sobrellevando el miedo y la represión. Volver a reunirse constituía una acción tan peligrosa como sentidamente necesaria. El dramaturgo Gregory Cohen, actor relevante del movimiento cultural universitario, asocia este período a la necesidad básica de existir en sociedad: «se trata de existir, de seres oscuros que buscan hacerse visibles». Y es que estos años son para el movimiento juvenil la instancia en que se recompone el yo con el nosotros, cuando la búsqueda identitaria que caracteriza el ser joven, vuelve a fijar su vista en un futuro que comprende su propia acción al interior de la historia.

a) Acción sociocultural y movimiento juvenil poblacional

Festivales solidarios en Renca

Dos festivales solidarios realizó Renca en las primeras semanas de septiembre y octubre, respectivamente, con el fin de reunir fondos para los comedores infantiles, combatir la cesantía y ayudar a los pobladores de las zonas marginales. Así, en los primeros días de septiembre se realizó el segundo 
festival «Jesús canta en Renca», premiándose al joven compositor Leopoldo Faúndez, por su tema «Juan tristeza». Posteriormente, y también con apoyo de las parroquias poblacionales, se realizó durante la primera semana de octubre «El tercer festival solidario de la parroquia Padre Hurtado», con el triunfo del joven José Polanco por su obra «Morir al lado de mi amor», ante una asistencia de más de cinco mil personas. La Bicicleta Nº2. Revista de la actividad artística. Diciembre 1978.

En las poblaciones, las acciones destinadas a constituir organizaciones juveniles, partían desde los grupos de amigos y los partidos políticos. Estos últimos, en su rearticulación, apostaban a posicionarse en el espacio social, promoviendo el surgimiento de organizaciones, mientras aquellos que hacían esfuerzos por construir organización y estaban fuera de los partidos, veían en lo político partidista el ofrecimiento de una trascendencia que iba más allá de lo local en los desafíos que implicaba una lucha antidictatorial. De esta forma, las construcciones desarrolladas en ambos niveles, la organización social y el partido, se requerían mutuamente y se fusionaban en el espacio de una Iglesia Católica que, las más de las veces, colaboraba de forma abierta y sin limitar la autonomía de las nacientes organizaciones. Este apoyo fue fundamental para las organizaciones, puesto que las viejas instancias vecinales estaban todas intervenidas por el régimen y no había libertad para ocupar los espacios públicos.

Yo a los 13 años comencé a militar en la 'jota', que en realidad era un grupo de cabros que estabamos vinculados a cosas como rayados, tirar panfletos [etc.] ... En eso nos pilló el golpe... entonces, en la población, yo diría que quedamos sueltos, porque todos los dirigentes culturales, políticos, no estaban, se fueron todos... había un miedo en los más jóvenes... [después en 1975, 76] A pesar de que éramos adolescentes... teníamos la claridad de que había que hacer algo, ...formamos un club deportivo, jugábamos a la pelota y conversábamos... Hicimos nuestros primeros rayados organizados, firmábamos con una erre de resistencia... allí nosotros recién decidimos conectarnos ya políticamente con alguien, comenzamos a promovernos, y lo que aparece como más concreto en ese sector es el MAPU Obrero Campesino... Yo recuerdo que tuvimos un encuentro en el cerro, y decidimos meternos a la Iglesia Católica, ir a conversar con el cura , en la más buena onda, decir quiénes somos, a qué venimos y qué queremos. El cura nos recibió súper bien, más de lo que nosotros esperábamos (no éramos gente de Iglesia)... Ya no éramos de la esquina, ni de la casa de algún compañero, sino que ya teníamos un lugar sin condiciones. El cura nos dijo: 'ya, ustedes tienen que venir a misa, tienen que ser un grupo pastoral', y nos pusimos Centro Cultural Cristiano de la Capilla del Señor de Renca (Hugo H., poblador de Renca). 
Este ejemplo se repite en diversos sectores y da cuenta de una apuesta por aglutinar a los jóvenes en torno a una acción cultural que reconstruyera simbólicamente los nexos con proyectos de cambio social. La identidad con estos proyectos era también un reencuentro con la historia reciente, que vivida como memoria prohibida, se conservaba junto al deseo de volver a sentirse protagonista de la historia. Ello se manifestaba en una serie de talleres artísticos, festivales y actos masivos en donde los lenguajes del arte permitían expresar implícitamente un sentir antidictatorial de cambio social. El espacio de la Iglesia otorgaba una seguridad que no era posible encontrar en otro lugar. Ahí la complicidad permitía ahorrarse palabras y el aglutinamiento físico de los sujetos otorgaba la certeza que la derrota no había sido completa, que los pobladores podrían nuevamente luchar por incidir en su realidad.

Por otro lado, la identidad partidaria y las lógicas de acción emanadas de ésta, se mezclaban con aquellas originadas en la horizontalidad propia de los grupos de amigos, aun cuando ya comenzaban a separarse los espacios relacionados con las motivaciones generacionales, el arte y la acción cultural, de aquellos espacios específicamente dispuestos para la planificación de acciones, formación y discusiones de corte político asociadas directamente a partidos o premilitancias de éstos.

Empecé a los doce. Fines del 77, en la parroquia San Pedro San Pablo... Me hice de un amigo en la micro, el me dijo: sabí que yo soy de un grupo juvenil que se llama Lincoyán y te invito, y yo fui. A mí me gustaba cantar, me gustaba el teatro, entonces tenía un espacio en el grupo... En ese tiempo, había una opción bastante clara por el tema de la cultura y del arte, se desarrollaba harto el tema del teatro, pero teatro con harto contenido social, de crítica. Había una obra que era con animales como en la granja de Orwel, los animales que tenían diferentes roles y ahí yo empecé a cachar que el cuento tenía su cosa por debajo. Había unos locos que participaban en el grupo que eran bastante más viejos que yo, ellos tenían entre 18 y 22 . Y que yo cachaba que tenían como conversas paralelas, que era el grupo que se juntaba, planificaba la reunión, que conducía el grupo, que tenían relaciones con otros grupos del sector, Joao Goular, Malaquías Concha, San Gregorio... Me empezaron a hacer algunas invitaciones a conversar conmigo más de política, a cachar un poco cuál era la opinión que tenía respecto a lo que estaba pasando en el país y cosas por el estilo... Con el tiempo empecé a cachar que la estructura partidaria de ellos era el MAPU... Por las condiciones que tenía de ser un partido de cuadros ahí había que cumplir la norma de premilitancia, primero ligado a un comité de resistencia, después de premilitancia, después de militancia. Ahí, después cuando yo me metí a militar 


\begin{abstract}
derechamente tenía unos trece o catorce... Entonces el centro juvenil pasa a ser tu espacio de militancia en alguna medida, pero las acciones que se desarrollaban políticamente por ejemplo en términos de agitación y propaganda nunca están ligadas al centro juvenil, o no se conversa en la reunión del grupo... eso se hace en el comité de resistencia que funciona paralelo, con una orgánica distinta. Pero en el comité de resistencia se conversa respecto de las líneas que hay que desarrollar al interior del centro juvenil, entonces pasa a ser una especie de dirección paralela la orgánica política (Verónica, La Granja).
\end{abstract}

Por su parte, el régimen intentaba evitar la reconstrucción identitaria de los jóvenes respecto a su accionar sociopolítico y cultural, proponiendo la imagen de un joven que se hiciera a sí mismo en torno al consumo de los símbolos que el mercado asociaba a lo juvenil. Un boom económico creado a costa de créditos externos, permitía que esta oferta contase con demanda. Usar las mismas zapatillas de Gildemeister o la chaqueta de Elías Figueroa, bailar como Travolta en la discoteque, comprar los discos de Julio Iglesias y ver el desfile de millones y los escotes de Raquel Argandoña en Festival de Viña, era lo que el régimen ofrecía a los jóvenes como mundo al que admirar y en el que identificarse. Una cultura oficial que representaba a la juventud como una unidad homogénea que disfrutaba, hacía deporte y amaba a su patria como lo habían hecho los jóvenes combatientes de la guerra del Pacífico en 1879. Una cultura que se articulaba en torno a productos importados carentes de contenidos sociales (pues llegaba la onda disco, pero no el punk) y que reservaba lo nacional a cantantes de televisión que ni siquiera grababan discos propios, pues como nunca los discos, libros y eventos, habían visto estancada su producción. Asumiendo este contexto, la resistencia sociocultural busca anteponerse al boom oficial y recuperar elementos propios con tradición en el desarrollo de las artes como el folklore, el teatro y la literatura chilena y latinoamericana. Se lucha contra los espacios de la diversión sin crítica y por ello es común en los testimonios de época escuchar como se hace referencia a las diferencias entre aquellos jóvenes que «viven como pajaritos» sin saber el lado oscuro del país, y aquellos que buscan comunicar los problemas sociales, asumirlos y luchar contra ellos «haciendo conciencia» por medio de los instrumentos que daba el arte.

Con estas motivaciones y con la Iglesia Católica como espacio eje, las redes socioculturales de la juventud popular organizada, se amplían a partir de las redes parroquiales. Los festivales de música y teatro se suceden de una comuna a otra apelando a la paz, la vida y a 
la imagen de un Jesús humano. Cada canción, obra o poema debía ser leído «entre líneas» para captar su carga antisistémica. Se trataba, sin duda, de una cultura opositora, pero de una oposición que apelaba a simbologías de la reconstrucción organizativa y la resistencia, sin explicitar un discurso de rechazo al régimen.

En 1978 Eduardo Peralta ganaba el festival «Una canción para Jesús» con el tema «El hombre es una flecha dirigida».

Y si el hombre es flecha, por qué lo vigilan, por qué le mutilan su carrera loca, por qué le tapan la boca, por qué le apagan la fe.

Esa misma fecha se celebraba el año internacional de los derechos humanos y la Vicaría de la Solidaridad organizaba el encuentro cultural «Todo hombre tiene derecho a ser persona», en donde se premiaban trabajos de diversas artes que tenían como tema central los derechos humanos. Era la pintura, el afiche, la literatura, posibilidades de expresar la mezcla de esperanza y desesperanza que cada sujeto vivía en su interior y luchaba entonces por comunicarlas y vivirlas colectivamente:

Al presentar problemas reales del hombre, supimos de luces y sombras, de penas y alegrías: la ingenuidad del niño que afirma su derecho a jugar, así como el reclamo del exiliado que afirma el derecho a vivir en su patria, la fuerza del amor y la angustia del cesante. ${ }^{3}$

En cada espacio que se ganaba para la creación artística, el sentido sociopolítico era implícito en figuras y símbolos que no sólo constituían una apuesta artística, pues las metáforas eran verdaderos resquicios para eludir una represión que no dejaba de hacerse presente en relegaciones, detenciones, muertes callejeras, desapariciones y exilios, que la prensa de la época presentaba como realidad normal, aunque los «delitos» fuesen situaciones tan simples como tirar panfletos o hacer declaraciones opositoras.

'No hay que agregar más sobre Illapu’, manifestó a La Segunda el ministro del interior Sergio Fernández. Este conjunto musical chileno no pudo ingresar ayer al país por disposición de las autoridades. Según el comunicado de DINACOS, estos artistas son 'activistas marxistas que participan en la campaña de desprestigio de Chile en el exterior’. La Segunda, 8 de octubre de 1981. pintura infantil». Arzobispado de Santiago, Vicaría de la Solidaridad, Santiago, 1978, p. 4. 
Por lanzar panfletos expulsan del país a estudiante universitario. Afectado, Joaquín Vidal Mora, de 23 años viajará en las próximas horas a Francia. Al momento de ser detenido fue baleado en una pierna por la policía uniformada. Fallo de extrañamiento — 154 días - emanó desde la corte suprema. La Segunda, 11 de agosto de 1982.

En este contexto, desde la población se tomaban precauciones para que las reuniones no fuesen prohibidas y perseguidos sus organizadores. Represión avalada por una prensa que, las pocas veces que mencionaba el quehacer cultural de las poblaciones, lo presentaba como un activismo marxista al amparo de la Iglesia, como lo hizo cuando denunció el trabajo de las arpilleras:

Los tapices de la difamación. Obras artesanales con mensajes son enviadas al exterior por la Vicaría de la Solidaridad. Este tapiz, confeccionado e ideado por 'artesanos' de la Vicaría de la Solidaridad, muestra a un grupo de mujeres que, junto a sus hijos, tratan de ver a sus familiares imaginariamente detenidos en Dos Alamos. La Segunda, 11 de abril de 1978.

En actos que incluso tenían presencia policial uniformada o civil, se recurría a símbolos y códigos que en su lenguaje no directo crearan un ambiente en que la complicidad silenciosa de la cultura antimilitarista se reconociera. Palomas, ponchos, folklore, canciones de Víctor Jara o Violeta Parra, cuyos discos permanecían ocultos o con otras carátulas para burlar allanamientos, hacían un conjunto en que los seres oscuros comenzaban a verse los rostros, cada vez de forma más masiva, cada vez con mayor control del miedo.

\section{b) Movimiento sociocultural en las universidades}

98 detenidos en una «Peña» por realizar un mitin político. Cerca de cien personas, la mayoría de ellas, estudiantes universitarios, fueron detenidas cuando participaban en una concentración política en el interior de una peña folklórica ubicada en la calle Huérfanos. La policía, junto con detener a los participantes en el acto, se incautó de gran cantidad de material de carácter subversivo. ...La citación a la reunión había sido hecha mediante panfletos mimeografiados en los cuales se señala textualmente 'Gran

acto artístico. El arte y el canto se unen para solidarizar con los alumnos sancionados, el día jueves doce de junio, a las 19:30 horas'.

Se señaló que en el lugar fueron detenidos 69 hombres y 29 mujeres... Hasta el mediodía de hoy los hombres permanecían detenidos en el interior de la primera comisaría de carabineros 
y las mujeres en la novena comisaría. Según se expresó, todos los detenidos estaban a disposición del ministerio del interior. Por otra parte vecinos del sector señalaron que la peña funcionaba en ese lugar desde hace un año todos los días, a partir de las 17 horas. Indicaron al mismo tiempo que 'Nos llamaba la atención que constantemente llegaran al lugar personas con maletín'. La Segunda, 13 de junio de 1980.

La reconstrucción de un tejido social juvenil, se vive de forma similar en las universidades. Aquí jugó un papel importante la agrupación cultural universitaria (ACU) formada en 1977 a partir de una serie de talleres culturales que habían logrado articularse. La ACU reunió tales talleres, incentivó la formación de otros, y organizó una serie de festivales y actos en que éstos presentaban sus trabajos e intercambiaban experiencias. ${ }^{4}$

Desde la ACU, las expresiones artísticas manifestaron el dolor que significó el golpe militar, la impotencia ante el autoritarismo y el deseo de recuperar la esperanza en pos de derrocar la dictadura y construir una nueva sociedad. Todo ello de forma velada, en canciones, poemas y obras de teatro cargadas de figuras que los jóvenes debían aprender a descifrar, así como melodías y símbolos que ligaban a los estudiantes con la cultura prohibida de antes del 73. Es así como en el tercer festival del cantar universitario «La universidad canta por la vida y por la paz» su anunciador Gregory Cohen leía:

Una vez más se muestra el trabajo cultural de los universitarios. Esta vez en la canción. Pero a pesar de todo cantamos. Una larga y creciente vibración, eludiendo muecas y cortapisas arriba, en un lugar y anteponiéndose al silencio. Ahora es el cantar, el teatro, la literatura, la plástica, todas ellas juntas en el pedestal de la nobleza del hombre, defendiendo el sentido de la vida, del amor, de la libre creación. Llegarán todos esos deseos porque no nos son ajenos, no nos son extraños. Respiraremos y no habrá necesidad de seleccionar el aire; conviviremos porque nadie estará fuera de lugar; renaceremos porque no hay otra posibilidad, ya que después de los espasmos habrá luz una bella intención de vivir, por eso y ahí ¡Cantaremos! ${ }^{5}$

La intensa actividad cultural desplegada por la ACU no es aceptada por una universidad intervenida que le niega sus espacios en

Para el estudio de este período del movimiento estudiantil, ver Ricardo Brodsky y Ramiro Pizarro: «La constitución del movimiento estudiantil como proceso de aprendizaje político», y Roberto Brodsky: «La ACU ha muerto, ¡que viva la ACU!». Ambos en Irene Agurto Irene et al., op. cit. 
complicidad con una federación de estudiantes FECECH, designada por las autoridades militares. El dirigente de esta última, Patricio Zamora, declaraba en 1980:

Esta agrupación no es representativa de los estudiantes de la Universidad de Chile y no cuenta con el apoyo ni reconocimiento de la federación de centros de alumnos de la Universidad de Chile FECECH, único organismo legítimo que canaliza las inquietudes estudiantiles. Es mi deber señalar que los que los fines de la ACU son netamente políticos y que tras sus actividades supuestamente culturales sólo buscan el compromiso ideológico de los estudiantes. ${ }^{6}$

A lo que los dirigentes de la ACU Patricio Lanfranco y Juan Valladares replicaban:

Ante el cuestionamiento que el joven Zamora hace sobre la legitimidad de nuestra agrupación, somos enfáticos en declarar que ésta ha sido otorgada por la comunidad universitaria al organizarse en más de 50 talleres afiliados a la ACU, participar en un número superior a las tres mil personas en el festival de teatro universitario de 1980; participar con 5000 asistentes en el Caupolicán el tres de noviembre de 1979; financiar la publicación permanente de nuestra revista La Ciruela y participar activamente en las jornadas culturales que organizan mes a mes los talleres de la ACU en las distintas facultades de la Universidad. ${ }^{7}$

Pese las dificultades, la ACU se mantiene y logra impulsar multitudinarios festivales y actos en que destacan dramaturgos como Gregory Cohen, poetas como Armando Rubio y Rodrigo Lira, y músicos como el grupo «Santiago del Nuevo Extremo».

Este último, en su tema «Simplemente» abordaba la disyuntiva histórica de una generación que pesándole la violenta derrota del proyecto social de la Unidad Popular que vivieron siendo muy jóvenes, adolescentes o niños, busca recomponer la esperanza como paso inicial para construir un nuevo proyecto de emancipación social:

La verdad es que no puedo mantener mi nombre atado a los días y a los hombres que me vieron derrotado... Enderézate y préstale atención a lo que digo porque yo estoy cantando por la voz de mis amigos. Simplemente que estas cosas son de todo el que las sienta y es mi voz la que las dice mas es de todos la conciencia, simplemente las verdades se van haciendo una sola y es valiente quien las dice más valiente en estas horas.

$6 \quad$ La Segunda, Santiago, 29 de octubre de 1980.

$7 \quad$ La Segunda, Santiago, 31 de octubre de 1980, p. 4. 
La ACU penetra fuertemente en un estudiantado que tras años de silencio postdictatorial, valora enormemente las instancias de expresión que ésta levanta. En referencia a ello, el poeta Rodrigo Lira escribe uno de sus «Epiglama oliengtaleh» leído en un acto de la rama literaria de la organización:

She pohtula que la ACU puntula cula la engfelmedá, la lokula, la neuloshi, la
sholedá, el shufrimiengto y el dolol — ke a ehta al tula del paltido leshultan
leshelah in chopol table, polke ni fu man do mali wana podlía lo uni vel shi
talio de I kielda ek pelimental tlan ki li da i felishidá— de manela que tenel
que integlashe lá pida mente a un tayel de cual quiel lama del alte o del
queachel al tihtico cultulal, o folmal uno kong loh komg pañeloh de culso o
de luta. $^{8}$

Paralelamente al movimiento cultural, se comienzan a generar las primeras manifestaciones explícitamente antidictatoriales. Desde pequeños mítines de denuncia de la represión del régimen y en contra de la política de financiamiento de la universidad, se llega a acciones de mayor convocatoria como una marcha por los detenidos desaparecidos en 1978 y la acción de más de mil estudiantes que un 4 de septiembre salieron del Pedagógico a la calle para reclamar democracia.

El Pedagógico, principal centro de la naciente agitación, impulsaba el primer paro en la universidad, en que los alumnos de castellano protestan por la expulsión de su profesora Malva Hernández, marginada de la universidad por sus actividades como madre de un detenido desaparecido. Los estudiantes del Pedagógico protagonizan también manifestaciones contra la "coordinación administrativa», compuesta por agentes de seguridad que en tanto funcionarios de la universidad, reprimían y denunciaban a los estudiantes. Tras la agresión que éstos llevan a cabo contra la dirigenta estudiantil Patricia Torres, los estudiantes atacan su oficina y tapian la entrada. Luego de esta acción serán sancionados 60 alumnos, lo que motiva la solidaridad de los estudiantes que paralizan las clases. Patricia Torres es perseguida y se le busca para ser procesada, mientras La Segunda escribe sobre el «largo historial de subversiva» de la estudiante. Posteriormente los alumnos iniciarán una huelga para que se aclare públicamente los motivos para detener a Torres. Los esfuerzos fueron en vano y Patricia Torres, al igual que muchos otros estudiantes, es detenida y una vez más, los recursos de amparo son rechazados por decenas.

8 Fragmento de «Epiglama oliengtaleh». Lira Rodrigo: Proyecto de obras completas. Santiago, Coedición Minga/Camaleón, 1984, p. 93. 
En este contexto el Pedagógico será castigado en 1981, cuando la ley general de universidades lo separe de la Universidad de Chile, así como a las sedes de provincia y al tecnológico de la Universidad. Mientras se acentuaba la represión mediante expulsiones y relegamientos, los diarios del régimen celebraban las medidas mostrando como los revoltosos se iban de la universidad, quedando un «nuevo Pedagógico» libre de los «lamentables espectáculos a los que estábamos acostumbrados». Entonces el nuevo rector de la ahora Academia Superior de Ciencias Pedagógicas daba la bienvenida a los alumnos:

Queremos hacer de ti un educador profesional y lo haremos, aunque a veces te disguste o no, ni te resulte claro el por qué de los deberes que se exijan. Comprenderás algún día que para aprender a mandar debes aprender primero a obedecer. ${ }^{9}$

Las desgracias también golpeaban el movimiento cultural en otros sentidos, cuando los estudiantes vieron morir a dos poetas símbolos de la vida cultural universitaria: Armando Rubio que cae de un sexto piso en diciembre de 1980 y Rodrigo Lira que se suicida un año después. El primero muere el mismo día que un desquiciado dispara contra John Lennon en Nueva York y el Pedagógico llora ambas muertes organizando homenajes para quienes ya sentían como símbolos de su generación. Lira, por su parte, cargando con un diagnóstico de esquizofrenia, está un año planificando su suicidio. Sueña con inmolarse en la «llama de la libertad» para lo que tenía unos jeans con poemas escritos en los bolsillos que mojaría en bencina, mientras en su casa dejaría una réplica de los mismos pantalones. Finalmente se corta las venas en una tina de baño, como lo adelantara en su poema hecho a cinco años del golpe militar «4 tres cientos setenta y cinco y un 366 de onces»: "Suave, callado el loro, morirse. O quedarse en la vereda como un pedazo más grande que el promedio de basura saboreando algo así como un candi masticable o un goyak y hasta incluso un caramelo bueno, de Serrano, o fino de Ambrosoli, pero muriéndose, muriéndose sin alharaca, muriéndose».

La ACU se resentía y pronto dejaría de existir. En agosto de 1981, seis meses después de su última edición se edita la revista de la agrupación La Ciruela, ésta muestra en su portada como una estatua de Milton Friedman reemplaza a la de Andrés Bello, mientras desde la

$9 \quad$ Citado en Cristian Warken: «John Lennon y la ley general de universidades». Perspectivas Nº6. Santiago, mayo de 1981. 
mano del economista cae una bomba que lleva las siglas de la ley general de universidades. Desde su editorial a su fin, pasando por los cómic del centro (el cuesco de la ciruela), se notaba una mezcla de decepción con esperanza del volver a levantar el movimiento:

Bienvenidos a las academias, universidades y ex universidades, donde Ud. podrá encontrar todo tipo de carreras, cortas y largas, con status universitario y sin, a los precios más convenientes del mercado. Se otorgan créditos a veces... Vaya pues, esta dulzona y semiagria, a veces ciruela para ustedes... La ciruela, incansablemente, florece siempre antes de la primavera.

Este tipo de movimiento universitario decaía dejando las bases para un movimiento estudiantil que recuperará las federaciones y masificará la confrontación con el régimen en las calles, en lo que usualmente se conoce como movimiento juvenil de los ochenta.

\section{c) Hacia la voz de los 80}

La lucha por efectuar hechos políticos en el espacio público como las protestas nacionales, no hubiese sido posible sin el período de reconstrucción de los sujetos colectivos y la pérdida del miedo que se desarrolla a fines del 70 y principios del 80. En la nueva década las organizaciones juveniles poblacionales siguen de pie y en la universidad se democratizan las federaciones. Sin embargo, se trata de un tipo distinto de organización en que las lógicas de acción de los partidos serán más fuertes, perdiendo protagonismo todas aquellas instancias centradas en las motivaciones generacionales de expresar el ser joven a través de la acción sociocultural, así como aquellas orgánicas más horizontales de los talleres. La urgencia del hecho político callejero postergó en parte el quehacer artístico cultural que se había logrado desplegar. Años después se buscará recomponer, atendiendo a que su importancia radicaba no sólo en tanto medio para la acción transformadora, sino como elemento constitutivo de la propia transformación.

\section{EL QUIEBRE TRANSICIONAL, EL EJE SOCIOCULTURAL Y LA RECONSTRUCCIÓN ORGANIZATIVA DE LOS JÓVENES}

Tras la gran desarticulación de organizaciones durante la transición política y el desprestigio de los partidos como ejes de la acción política, ¿pueden las nuevas organizaciones sociales de los jóvenes apostar a desarrollar un accionar sociopolítico? Desde un orden que 
glorifica la mantención de las estructuras sistémicas ocultando los conflictos en un mar de consensos y lógicas de responsabilidad, es coherente que se estigmatice a los jóvenes como sujetos «apolíticos» que no tendrían interés en ejercer ciudadanía. Ante esto conviene preguntarse en qué medida los nuevos tipos de asociaciones juveniles contienen un potencial de intervención y transformación de la realidad.

La acción ciudadana se ejerce desde las dimensiones y asociaciones sociales y políticas. Ambos conceptos, lo social, lo político, no son diferentes en términos de esencia. Sin embargo, históricamente ha habido instancias en que se han separado y creado estructuras específicas para tales dimensiones de la acción ciudadana. Entonces, lo social se ha remitido al accionar desde las realidades particulares e identidades centradas en tales particularismos; y lo político, al accionar en espacios públicos generales y asociaciones específicas para tal labor.

Partidos políticos por un lado, organizaciones y movimientos sociales por otro. Hay quienes asumen esta separación y quienes no, y en tales concepciones radicarán las representaciones de accionar ciudadano. En parte, los Estados modernos se basan en la separación de tales ámbitos, teniendo en el sistema de partidos una especificidad de lo político que sería diferente al accionar de los movimientos sociales. Pero es importante tener claro que tales divisiones han sido modalidades del ejercicio ciudadano, modalidades humanas que no tienen nada de naturales. De hecho, existen múltiples ejemplos de instancias que han buscado unir tales esferas de acción rescatando una concepción de política asociada al origen social del concepto, definición que surge en la Grecia clásica y que ve en el ser humano un ente político cuyo accionar propositivo parte desde sus mundos más inmediatos y, desde ahí, se proyecta a lo público como acción orientada a la construcción de sociedad.

Es justamente el desarrollo de esta última variante una potencialidad de las nuevas organizaciones socioculturales de los jóvenes, las que, caracterizadas por sus valoraciones de autonomía y horizontalidad organizacional, constituyen gérmenes de un accionar político que nace desde lógicas e identidades sociales. De desarrollarse estas tendencias en dirección a la solidificación de redes que apunten cada vez más a los espacios públicos, podría darse real forma a un movimiento social juvenil que haga de la acción cultural una opción por la construcción sociopolítica de la realidad. 
a) De los partidos a los colectivos. Los desafíos de la autonomía sociocultural y las representaciones de la acción política

Viéndose disminuida la presencia de estructuras institucionales o partidarias, las organizaciones juveniles comienzan, a partir del año 90, a tomar las formas y lógicas de acción propias de las instancias básicas de sociabilidad en que encuentran su origen, es decir, los grupos de amistades. Se trata de organizaciones que privilegian la horizontalidad, la trasparencia de las informaciones, la autogestión y la independencia respecto a instancias e instituciones externas. Quienes iniciaron esta tendencia en los noventa fueron amistades que, siendo adolescentes, participaron en organizaciones de los ochenta o conocieron y adscribieron a las expectativas de transformación social de éstas. Nuevamente aparece en la reconstrucción organizacional una suerte de generación intermedia que sirve de puente de memoria y crítica histórica, haciendo posible el aprendizaje y la búsqueda de nuevas formas organizativas.

[El Kiltro] venía con una experiencia previa. Principalmente con jóvenes que tenían experiencia previa en el trabajo popular y que habían vivido esta especie de frustración en torno a lo que era la transición, digamos, el proceso de transición de los años 90, y esta sensación de vacío que hubo durante los dos primeros años y que duró diría yo más tiempo, pero que con El Kiltro, naciendo como organización nueva, pudo intentar digamos desarrollar un trabajo, un trabajo con una línea ideológica y política en términos de lo social. Sin ser partido político y sin ser militantes de partidos políticos. Porque además nosotros como jóvenes alguna vez también estuvimos vinculados a los partidos políticos de izquierda y militantes... Y de ahí intentando construir una nueva utopía como organización social. Intentando apoderarse del discurso político, pero sin la necesidad de ser partido político y sin la necesidad de militar en alguno de los partidos políticos tradicionales. Entonces intentamos ir validando nuestros espacios con un discurso muy juvenil, en términos sobre todo, digamos, de lo rebelde entre comillas que son los jóvenes, en términos, digamos, de enfrentarse al modelo, de la búsqueda de solución a las problemáticas sociales (Pato, Colectivo Cultural El Kiltro, Huechuraba).

En general, el tipo de organizaciones que se asocia a esta generación intermedia, opta por la constitución de colectivos que desconfían de las instituciones. Si obtienen o no personalidad jurídica suele generar discusiones, pues se resisten a las lógicas de cargos que ésta conlleva. En ocasiones obtienen tal rango jurídico como un mecanismo para la obtención de recursos, pero tomando como un simulacro las elecciones de directivas. 
Era incluso al cachipún, quién quiere ser tesorero, no nos importaba. Jugábamos al cargar la mata. Y así, en realidad no nos interesaba, nos interesaba tener un número porque eso nos garantizaba tener la plata... Dijimos instrumentalicemos esta huevá, esta huevá tiene que ser un instrumento (Pato, El Kiltro, Huechuraba).

Así han surgido importantes organizaciones que han podido construir redes, hacer encuentros y muchas de ellas, plantearse como instancias socioculturales con poder transformador. Es el caso paradigmático de la organización «Perro Muerto» que se define como un «proyecto mágico que camina con la toma cultural» y que ha contado con su presencia en múltiples lugares en donde se han tomado los espacios públicos para la libre expresión artística con sentido social crítico.

No nos dejan hablar, nos ponen representantes para todo. Si nos estafan en la compra de una casa, hay que morir pollo, para eso está Nelson Ávila. Si nos suben la micro, nos cagan con la salud o ya no respiramos por el smog, no decimos ni pío, para eso está el virtuoso Girardi. Si la cosa se pone fea y ya es problema de derechos humanos, aparece la infaltable tía Gladys. Al parecer, para ellos somos un montón de huevones nomás, que no podemos opinar. Así quedamos, cero sindicalización, sin salud, previsión ni educación. Para nosotros nada, todo para ellos. Pero le andamos buscando, sin descanso, así nacemos.

Perro Muerto pretende ser algo más que una revista. Es el espacio en que tu puedes patalear y defenderte a ti mismo. ${ }^{10}$

De la misma forma, en la universidad han surgido múltiples colectivos culturales que se relacionan entre sí y han podido incluso trascender al espacio universitario y sus miembros seguir organizándose más allá de lo que duran las carreras académicas. Una forma que ha permitido tal perdurabilidad ha sido el que estos colectivos han buscado ampliar su gestión a ámbitos barriales, levantado centros culturales, juveniles, o insertándose en otras iniciativas, entregando los saberes propios en un intercambio con los saberes locales.

El proceso de desarrollo de estas instancias aún es germinal transcurridos ya más de diez años de la transición, pues la consolidación de los colectivos, centros culturales y sus redes cuenta con ritmos sumamente lentos. Optándose en gran medida por fórmulas más autónomas ya no es posible sumarse a redes articuladas desde partidos e instituciones. Las posibilidades de generar movimientos sociocultura-

10 Revista Perro Muerto No2, Santiago, diciembre del 2000. 
les que desde su independencia aspiren a desarrollar acción cultural e impulsar cambios sociales, están presentes en una multiplicidad de instancias que a diario experimentan medios para la interrelación y la intervención en ámbitos más públicos. Es una experiencia sumamente nueva para un país en que los movimientos sociales, desde la década del treinta, evolucionaban con lazos de dependencia respecto a las estructuras partidarias.

b) Hip Hop, batucada y capoera. Al margen de la globalización sistémica, lo popular por sobre lo nacional

En la plaza de la Población Dávila, se junta todos los días un grupo de jóvenes que practican el Break Dance. Baile que surge hace décadas en los barrios «negros» de las ciudades de Estados Unidos junto con muchas otras expresiones de la llamada cultura Hip Hop. De gran exigencia de ritmo, fuerza y elasticidad, es resistente en la «medida de lo posible» a la comercialización y es, casi por definición, popular, urbano y callejero. Contorciones y saltos que de año a año cambian, dejando libre paso a la creación continua que se exhibe a quien desee detenerse a observar de Nueva York a Santiago de Chile, del Bronks a la Dávila.

Yo me llamo Jorge, tengo dieciséis años, bailo hace un año y medio más o menos y de ahí que no me despego de las pistas. Me gusta caleta bailar, pienso a cada rato en la hueá, porque me gusta, lo que más hago es bailar y aunque no esté bailando en un piso, bailo en mi mente (Jorge).

Jorge y Miguel más otros 6 jóvenes se juntan desde hace dos años en la plaza de la población a bailar. Si ven que alguien se interesa le enseñan. Se acercan, de hecho, muchos niños que les llama la atención el baile y piden instrucciones. Algunos se cansan de las caídas y los golpes, pero otros insisten. Hoy hay tres niños que todavía los siguen y piensan que podrán ser break. A ellos les gusta enseñar porque sienten que es así como el baile queda y puede seguir evolucionando pues «el break nunca se va a terminar de hacer».

Les gusta mostrarse, ser reconocidos por la población y que vecinos los admiren y les lleven refrescos para pasar el calor y el cansancio. Cuando tienen la posibilidad de hacer alguna exhibición practican horas para que todo salga perfecto. $\mathrm{Y}$ es que están conscientes que lo que presentan no es lo mismo que a diario bailan para ellos. Son otras las valoraciones de los que están en la cultura del break 
respecto a los que no, y asumen que para gente ajena a consideraciones más técnicas, se debe hacer un «show» especial. En el baile está lo que ellos son. Si se respeta el baile se les respeta a ellos, por lo que el break es clave para darse a conocer a la comunidad como quieren ser reconocidos.

Por todo eso insisten en lo suyo, aunque tengan que ser enyesados una y otra vez por malas caídas. Incomprendidos por algunos, sacados de la junta de vecinos porque rayan el piso, siendo padre adolescente o joven cesante, alivian los momentos de desesperanza en compañía de los pares y haciendo lo que les gusta hacer: bailar. El Break opera como centro de constitución del «nosotros», es la identidad que en idioma inglés mira a un mundo global. Pero a una globalidad distinta a la del internet, los mall y las multinacionales. El Break nos habla de una globalidad cultural de los pobres, mirada mundial de los barrios bajos de las urbes que desde Nueva York a Santiago ocupan las calles con piruetas y entrecortados movimientos. Tanto en un lugar como en otro, los jóvenes se toman las calles porque desean ser visto, porque es ahí donde se encuentran los amigos y se enfrentan las dificultades y goces de la vida, y por qué no decirlo, porque desde los márgenes de la exclusión social no se cuentan con otros lugares en donde hacer arte y cultura, desde la propia vivencia del ser joven.

En la población La Victoria un grupo de jóvenes conforma la batucada Wadantún. Aprendieron a tocar instrumentos en la población Santa Adriana, pero esa batucada se acabó y hoy tienen un grupo propio que de a poco lucha por juntar sus propios instrumentos.

Hacían peñas donde recibían el apoyo de otras organizaciones de la población, para conseguir lo que no tenían y requerían urgentemente, siendo esta carencia uno de los principales motores de su quehacer organizativo. Cuando conseguían instrumentos prestados, los jóvenes miraban éstos con una mezcla de alegría y sana envidia. Tambores alguna vez ganados por un proyecto de una ONG en La Pintana, que hoy ocupaban lugar estable en una bodega. - Pensar que nosotros tocamos y no tenemos con qué y aquí los tambores se llenan de polvo- . Tomaba cada uno el instrumento de su preferencia y comenzaban a tocar, una, dos, tres horas, tardes completas como si nunca más fueran a hacerlo.

En los momentos que cuentan con que tocar, buscan ser vistos, dar alegría y que la gente baile a su alrededor. Pero una de las principales motivaciones es tener movilidad. El batuquero tiene que ir de un lugar a otro, porque no puede saturar con su música en una sola 
parte. Su fin es ser siempre lo más novedosos posibles, nuevos ritmos en nuevos lugares. Para eso refuerzan sus lazos con organizaciones que van mucho más allá de los límites de su población. Si ellos organizan algo y bajan jóvenes desde Peñalolén a La Victoria, cuando ocurra al revés y sean estos otros los que soliciten su presencia, ellos gustosos irán. Es la reciprocidad organizativa en que se reconocen las organizaciones que trabajan desde el eje cultural. Organizaciones que amplían redes urbanas a partir de sus identidades juveniles, interviniendo con sonidos y bailes en barrios que de norte a sur conocen de las mismas luchas por una vida mejor, lugares en que la pobreza se regocija de vez en cuando, con espectáculos gratis que les recuerda que las solidaridades colectivas siguen siendo armas de transformación social, y de cierta forma, son parte de la propia transformación.

Es que igual nosotros, nos conocen igual harto... Nos gusta salir, nos gusta andar en diferentes partes y cuando tocamos en La Victoria, no sé, es para alguna ocasión especial (Rodrigo y Pato).

Al oeste de La Victoria se encuentra la población Lo Valledor Norte. Un grupo de niños que habitan unos block en tal sector, se juntan todas las semanas a practicar un baile de origen brasilero que es la capoera. Julio de 17 años es el que les enseña. Arman un círculo y entre palmas, cantos y algunos instrumentos comienzan a salir uno a uno a enfrentarse a un baile que simula ser una lucha. A veces alguien falla en la simulación y un pie choca con algún maxilar, pero entonces sólo ríen, pues se asume como riesgo de la danza. El grupo se llama Birunga, niebla africana que cumple las funciones de la camanchaca del norte chileno.

Para Julio su primer maestro fue Jorge, hace ya 4 años. Luego conocería a Ariel y el lo llevaría donde Cerio, un brasilero inválido que hablando poco español les indicaba desde su silla de ruedas cómo hacer cada movimiento a sus alumnos del grupo «Africa Brasil» en Maipú. Tiempo después bailaba cuando notó que los niños de su barrio lo observaban con admiración. Surgió entonces la idea de enseñar. Como Cerio «El padre» lo había hecho con él, Sunbi «El abuelo» con Cerio, y Kaisara, «El tatarabuelo», con Sunbi.

La Capoera se puede decir que es una familia, por ejemplo yo no sería el maestro ni el profesor yo soy el hermano mayor. El papá sería el Cerio, nuestro abuelo sería Sunbi que está en Brasil, el tatarabuelo sería Kaisara, y así la generación... En 1853 Kaisara, después viene Sunbi Silvestre, generación Silvestre, después generación Cerio (Julio). 
La enseñanza actúa como medio de trascendencia en esos niños que ya cuentan con un espacio propio a partir del cual crecer. Julio sentirá que provoca transformación en sus alumnos «hermanos menores», a la vez que se transforma a sí mismo y comienza a sentirse parte de una comunidad que antes le resultó ajena. Se siente satisfecho con que los muchachos ocupen su tiempo en conocerse a través del baile y no pasen las tardes esperando el tren para tirarle piedras, como lo han hecho todas las generaciones nacidas en el sector. Sabe que para los niños, el círculo del capoera es un lugar en donde ser reconocidos, pequeño mundo en que los golpes sólo son aparentes y la apariencia es juego. En el baile se interrumpe la violencia de la pobreza y los gritos son sólo de alegría y admiración. Oasis necesario para que los niños sigan siendo niños, aun cuando en sus poblaciones se deban endurecer tempranamente en medio de conflictos que no están en condiciones de entender. El capoera hace de los niños artistas admirados, delgados gimnastas que reciben aplausos por jugar, por apropiarse de las calles con saltos mortales y mirar desde las alturas a una población que sonríe en medio de la carencia. Como lo hacen tantos en Chile, como lo hacen en las favelas.

Cuando escuchamos una batucada, por ejemplo, la de La Victoria y de repente, oye, vamos caminado por la calle y un cabro chico 'oye vamos', se une uno, 'ya vamos' y al final todo el grupo, y así, puros buenos y llegamos así y dejamos la embarrada. Este hace unos mortales, lo tiro terrible lejos, la cabeza, onda dicen 'Uhh'.

Una mirada por las experiencias organizacionales aquí expuestas haría temblar a un conservador «intoxicado de patriotismo». Brek Dance, Batucada, Capoera, no son precisamente actividades surgidas en el valle del Maipo. Pero si nos internamos en los procesos desarrollados por los jóvenes comprenderemos que sus culturas, aun con nombres en portugués o inglés, les son propias. Son identidad no en cuanto la heredan, sino en cuanto la construyen, y esta construcción cruza los límites de las fronteras políticas, aunque no las atraviesen de modo inmutable, pues en cada localidad en que se desarrolle será de forma distinta.

La chilenidad queda en duda cuando comprobamos que La Dávila queda más cerca del Bronks que de Providencia. Una suerte de globalización de los márgenes urbanos o mundialización cultural de los pobres llega a las poblaciones de Santiago. Desde aquí se comparten las tensiones existenciales propias del ser joven, y las formas de 
enfrentar estas tensiones queda plasmada en el accionar sociocultural. $\mathrm{Y}$ es en este sentido que la vivencia social desde la carencia y el dramatismo de las tensiones que operan desde estas realidades constituyen denominadores comunes más poderosos en términos de identidad que la idea de nación como valor ajeno a dimensiones sociales.

Claro, o sea el hip-hop es algo grande que se relaciona con el graffiti, con el freestyle, que es el movimiento en la bicicleta todo eso, con el breakdance, con el canto, con todo eso se relaciona, con la vestimenta, todo eso es el hip-hop. Si ahora, si a mí me pregunta alguien tú quién soy, yo soy hiphop... El hip-hop está asociado a todo dentro así, es como una familia (Miguel).

Una clave para captar la dimensión ciudadana del accionar de este tipo de organizaciones, es el discurso que construyen respecto a los niveles de realidad socioeconómica en que están inmersos. La población, la ciudad, el país, aparecen como niveles que de lo particular a lo general son determinados por diversos factores. La pregunta es en qué medida el accionar propio se percibe incidiendo en tales niveles y constituye reconocimiento del potencial ciudadano.

Por ejemplo, la pobreza suele presentarse como una condición que siendo vivida en lo local, es representada como fruto de situaciones generales y dependiente de niveles de decisión estructurados en las alturas de los grandes poderes sistémicos, o como los mismos jóvenes los denominan, los poderes de «los de arriba».

Pregunta: pero, ¿por dónde piensan ustedes que podría pasar una solución? Para, ya no sólo económica de La Victoria, sino del país, con esto de la cesantía y la falta de dinero, ¿de quién depende la solución acá?

Respuesta: de arriba.

Si es que igual, por ser los empresarios yo los encuentro, son muy apretados, no quieren a lo mejor invertir en cosas, para así dar más trabajo y no sé, prefieren estar ellos con su plata segura así y dejan a los demás ahí, que se mueran de hambre (Rodrigo, Batucada La Victoria).

En los discursos de los jóvenes la desesperanza tiene el rostro de la pobreza estructural, la condición de carencia en la que no se vislumbraban posibilidades de transformación en que lo propio pueda incidir. En la desesperanza se depende de los «de arriba», de la economía en tanto situación determinada por otros sujetos.

Ésa es la forma de pensar que tenimos nosotros, si la gente que tiene el poder de mando, que tiene para hacer algo por la comunidad de repente y no 
lo hace, por parte mía yo no le doy mi apoyo ni mi voto a nadie (Miguel, Break Dance Población Dávila) .

La gran política, la del sistema de partidos a nivel nacional y las instituciones del Estado, aparece lejana. Independiente de si los jóvenes manifiestan o no interés en inscribirse en los registros electorales, lo clave es que no existe noción de una ciudadanía plena a través del voto. Por su parte, la pequeña política, esa que se vive en la población y sus organizaciones, en pocas ocasiones es representada en tanto «política». En general, y sobre todo los más jóvenes, asocian política sólo a la política institucional asociada al sistema de partidos y los poderes del Estado.

En los discursos de los jóvenes las perspectivas ciudadanas se representan como desesperanza ante niveles de efectividad social que aparecen tremendamente lejanos. No así el accionar más particular e inmediato ligado a la transformación del espacio público por medio del accionar cultural. Es en esta dirección que el sonido de la ciudadanía activa se escucha más fuerte, es ahí donde es posible gatillar procesos reconstructivos de un movimiento sociocultural juvenil con perspectivas de ejercer acción política desde su autonomía.

Se trata de salir a flote de la libertad de expresión del pueblo chileno, de la gente de Chile, porque la gente de Chile está muy aquí, japoneses, alemanes, estadounidenses, está todo así como que quieren apretar, trayendo culturas de otras cuestiones y por ahí quiere escaparse al teatro, por ahí quiere escaparse el payasito, por acá la batucada, pero todavía no se pueden escapar, entonces tienen que unirse así, unir las fuerzas y va explotar esa arte, esa arte callejera y ese día va a ser bacán, va haber arte en todos lados, va haber magia en todos lados (Julio, Capoera).

c) Hacia la voz del nuevo siglo

Tanto aquellas organizaciones más estructuradas que optan por trabajar sociopolíticamente desde el eje cultural, como aquellas iniciativas barriales que participan de determinada identidad que se expresa artísticamente, conforman hoy el panorama sociocultural desde el cual es posible impulsar un movimiento social juvenil. Tal tarea histórica aparece como sumamente novedosa para la sociedad chilena. Aun así, es posible rastrear en experiencias pasadas e incrementar una memoria histórica que sirva de insumo para la lucha sociocultural de los jóvenes. Éstas pueden ser tanto los centros culturales poblacionales que nacieron en dictadura y la agrupación cultural universitaria, como 
todas aquellas instancias que desde los más diversos ámbitos sociales, han visto en la gestión cultural un fin y un medio en la búsqueda de una sociedad más humana.

SANTIAGO, JUNIO DEL 2002 